\title{
Tumor Regression Score 2
}

National Cancer Institute

\section{Source}

National Cancer Institute. Tumor Regression Score 2. NCI Thesaurus. Code C155943.

A score on the Modified Ryan Scheme for Tumor Regression that indicates a partial response, defined as the presence of residual cancer with evident tumor regression but more than single cells or rare small groups of cancer cells. 